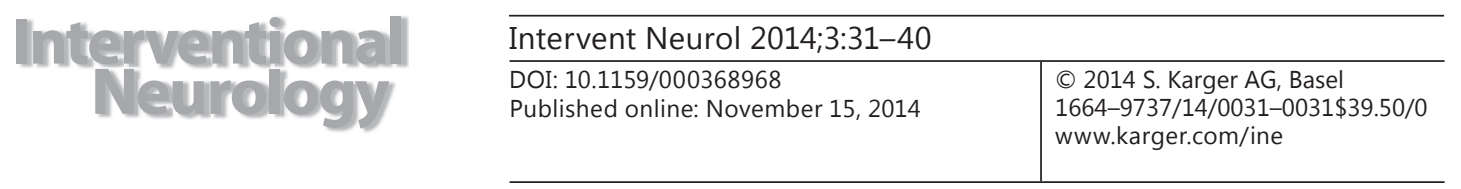

\title{
Review
}

\section{Endovascular Revascularization for Basilar Artery Occlusion}

\author{
Jacky T. Yeung ${ }^{a} \quad$ Charles C. Matouk ${ }^{a} \quad$ Ketan R. Bulsara ${ }^{a}$ Kevin N. Sheth ${ }^{b}$ \\ Departments of a Neurosurgery and ${ }^{b}$ Neurology, Yale School of Medicine, New Haven, \\ Conn., USA
}

\section{Key Words}

Endovascular revascularization · Basilar artery occlusion

\section{Abstract}

Basilar artery occlusion is one of the most devastating neurological conditions known to man. Though rare, patients with clinical syndromes localized to this anatomical region are often referred to acute stroke and endovascular units. Recent studies evaluating the efficacy of endovascular approaches to stroke have focused on anterior circulation syndromes. In this review, we examine the approaches to stroke syndromes due to basilar artery thrombosis. We share the relevant data for intravenous and intra-arterial tissue plasminogen activator as well as mechanical approaches to restoring perfusion in this critical area of the brain.

(C) 2014 S. Karger AG, Basel

\section{Introduction}

Acute basilar artery occlusion is a rare stroke syndrome comprising only $3 \%$ of all ischemic strokes [1,2]. Overall, the estimated incidence is approximately 1 patient per 100,000 person-years [3]. Although embolism from cardiac or infectious sources accounts for some acute basilar artery occlusions, the majority is a secondary consequence of atherosclerotic disease [4]. Acute basilar artery occlusion carries an exceptionally high morbidity and mortality rate of $80-90 \%$ without active intervention [5, 6]. A majority of reports in the liter- 
ature demonstrate an improved natural history with aggressive intervention [7]. However, the retrospective nature of a majority of these studies, the heterogeneity of management philosophies, and the rapid evolution of interventional treatment modalities over time make definitive statements regarding a best approach difficult [8-13].

Three neutral trials of endovascular therapy for acute ischemic stroke have recently been published in the New England Journal of Medicine (IMS III, Synthesis, and MR-RESCUE) [1416]. This has dampened the enthusiasm for endovascular therapies. However, patients with acute basilar artery occlusion were not well represented in these studies. Basilar artery occlusion is a devastating pathology that continues to warrant aggressive treatment. For example, in IMS III, only 4 patients with acute basilar artery occlusion underwent intraarterial (IA) therapy (and thrombolysis in cerebral infarction scores were not reported) [14]. Synthesis did not require patients with posterior circulation strokes to have basilar artery occlusions to be enrolled in the study and randomized to, and receive, endovascular therapy [15]. MR-RESCUE only included patients with anterior circulation strokes [16]. Unlike other stroke syndromes where significant controversy exists as to the role of endovascular therapy, the preponderance of evidence suggests that IA approaches may in fact impart a major survival advantage. In this review, we focus on the different modalities of IA therapy and their efficacy in the management of acute basilar artery occlusion.

\section{Intravenous Therapy}

Patients with acute ischemic stroke in the anterior circulation benefit from intravenous thrombolysis (IVT) within $4.5 \mathrm{~h}$ after symptom onset [17]. However, due to the devastating nature of basilar artery occlusions, the time to treatment is often extended beyond $4.5 \mathrm{~h}$. More than $67 \%$ of basilar artery occlusion patients present $>3 \mathrm{~h}$ after symptom onset, which is, in part, a reflection of the ill-defined symptoms and the diagnostic difficulties of this disease [18]. As the risk of poor functional outcome is proportional to the time to recanalization therapy, the need to achieve quicker recanalization is underscored [18]. Endovascular therapies have become an attractive modality to achieve this goal.

\section{Endovascular Treatment Options}

\section{IA Thrombolysis}

The use of IA tissue plasminogen activator (tPA) was first described over 30 years ago [19]. Therefore, it is perhaps surprising that the number of large-scale studies of IA thrombolysis in posterior circulation strokes remains small. In this regard, an Australian multicenter, randomized, controlled trial of IA urokinase in the treatment of acute posterior circulation ischemic stroke administered within $24 \mathrm{~h}$ of symptom onset was a foundational study. Only 16 patients were randomized; 8 patients received IA thrombolysis, and 4 of the patients died. Of the survivors, the 4-month modified Rankin Scale (mRS) score was 1 [20]. In the control group, 4 patients died. However, the 4-month mRS score in the stroke survivors was only 3 [20]. Although the study population was too small to draw statistically significant conclusions, the results suggested that IA thrombolytics may be beneficial for patients with acute vertebrobasilar occlusions.

Most other reports are case series that differ in treatment protocol and study methodology, making direct comparisons of study results difficult. In one of the largest case series involving 180 patients with acute vertebrobasilar occlusion treated with IA thrombolysis, complete and partial recanalizations were achieved in 55 and $19 \%$ of the cases, respectively 
[21]. Recanalization was significantly associated with a favorable outcome and negatively correlated with the volume of thrombus [21]. Neurologic outcome strongly correlated with pretreatment mRS score, age, and coma lasting $<4.5 \mathrm{~h}$ on univariate testing [21]. However, the duration of brainstem stroke symptoms and coma duration were not significant as independent variables for a favorable neurological outcome in multivariate testing [21]. In other words, the authors could not establish a time window that would exclude selected patients from IA fibrinolysis. This was corroborated in another, smaller study which showed no correlation between admission Glasgow Coma Scale (GCS) and 90-day mRS scores and indicated that equal numbers of patients with the good neurologic outcome of an mRS score of $\leq 1$ ( $n=$ 12) had a GCS score of $\leq 6$ or $>6$ at presentation [22]. The authors also argued that low GCS scores at presentation should not exclude patients from IA thrombolytic therapy [22].

A meta-analysis including 10 studies and 316 patients demonstrated a recanalization rate of $64 \%$, a mortality rate of $56 \%$, and a $48 \%$ absolute risk reduction of death $(\mathrm{p}<0.001)$ [23]. A consistent survival benefit was predicted by revascularization ( $87 \%$ nonrecanalized compared with $39 \%$ recanalized; $\mathrm{p}<0.001$ ). Since this meta-analysis included studies with a high degree of heterogeneity (in the timing of interventions, interventional technique, and outcome measurements), differences in neurological outcomes amongst survivors could not be adequately assessed. Notwithstanding these inherent limitations, there was a strong suggestion that IA thrombolytics reduce mortality in patients with acute basilar artery occlusions.

It is unclear at this time how IA therapy compares with IV therapy, due to the lack of randomized controlled trials. In a systematic review of published case series of substantial size reporting the outcome of basilar artery occlusion after IA thrombolysis or IVT, mortality or dependency were equally common between the two routes of medication delivery, i.e., $78 \%$ (59 of 76 ) and $76 \%$ (260 of 344), respectively ( $p=0.82$ ) [9]. The therapeutic windows in the studies were divided into the ultra-acute (within $6 \mathrm{~h}$ ) and acute (within $12 \mathrm{~h}$ ) [9]. Outcome scores approximating a 3-month outcome were used, if provided [9]. Although recanalization was achieved more frequently with IA delivery $(225$ of $344 ; 65 \%)$ than with IVT ( 40 of 76; 53\%; $\mathrm{p}=0.05$ ), there was no difference in survival rates and positive outcomes (IA vs. IV: 24 and 22\%) [9]. It is, therefore, reasonable to argue that IVT be performed in centers without the capability of IA delivery. Interestingly, studies in recent years have looked at the use of IVT to bridge the time gap until IA therapy is initiated [12, 24]. Pfefferkorn et al. [13] showed that initial IVT in a community hospital followed by IA thrombolysis in an interventional neuroradiology center may have higher efficacy than IA thrombolysis alone.

There is a paucity of data in the literature to establish the efficacy of IA thrombolysis in combination with IVT or other modalities such as IA stenting and mechanical thrombectomy in the treatment of acute basilar artery occlusion. The overall rate of symptomatic hemorrhage ranges from 0 to $14 \%$ in published studies [9, 22, 25-29]. Considering the poor natural history of the disease, this rate of symptomatic hemorrhage may be acceptable. Moreover, the rates of symptomatic hemorrhage appear to be lower with the more recent mechanical thrombectomy technologies. Multi-institutional randomized trials are needed to fill the many gaps in knowledge concerning IA thrombolysis.

\section{Angioplasty and Stenting}

Sundt et al. [30] reported the first intracranial angioplasty performed in a basilar artery. Recanalization of the intracranial vertebral and basilar arteries by angioplasty and/or stenting has since become an increasingly feasible option due to advances in endovascular treatment [31-33]. The focus of this paper is the management of acute thrombotic occlusion of the basilar artery, and we will therefore not focus on the management of intracranial atherosclerosis per se, a subject that is well reviewed elsewhere [34, 35]. 
Fig. 1. A 63-year-old female with a history of atrial fibrillation, but not anticoagulated, presented with $24 \mathrm{~h}$ of ophthalmoplegia, dysarthria, dysmetria, and a fluctuating level of consciousness. A head CT demonstrated an acute right cerebellar stroke and multiple old strokes in the bilateral occipital lobes and left thalamus. The Penumbra Stroke System was successfully used to remove the clot in her basilar artery and achieve complete revascularization.

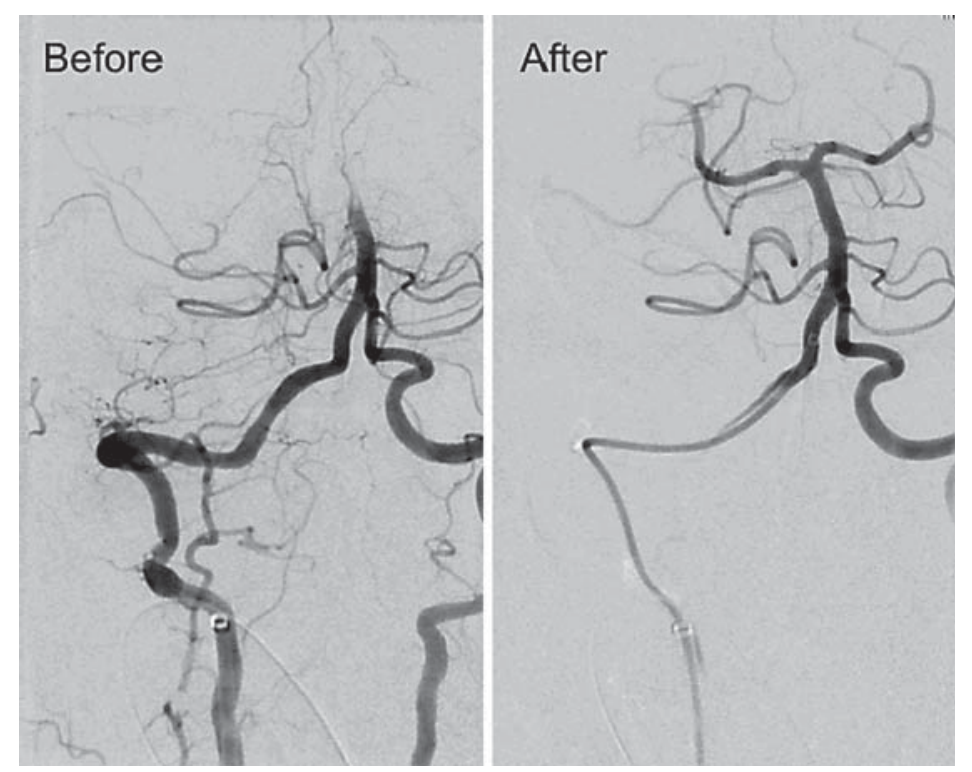

\section{IA Thrombectomy}

Mechanical thrombectomy has been shown to restore patency in large intracranial vessel occlusion in $41-54 \%$ of cases [36-39]. This treatment modality represents an alternative for those who fail conventional intravenous tPA therapy. The most common devices reported in the literature include Merci and Penumbra aspiration catheters, the Solitaire, and Trevo stent retrievers.

The Mechanical Embolus Removal in Cerebral Ischemia (MERCI) trial assessed the efficacy of mechanical thrombectomy using the Merci Retrieval System (Concentric Medical Inc.) within the first $8 \mathrm{~h}$ of acute ischemic stroke [37]. This prospective, nonrandomized, multicenter trial targeted patients who were ineligible for intravenous tPA therapy. Depending on whether the analysis was based on intention-to-treat or on actual deployment of the device, the recanalization rate ranged from 46 to $48 \%$, with clinically significant procedural complications occurring in $7.1 \%$ of patients with large-vessel occlusion. Specifically, $9 \%$ of the study population had basilar artery occlusion. Although the study grouped vertebral and basilar artery occlusions in one entity, the rate of recanalization was up to $50 \%$, and the 90-day mortality rate was 50\% [37]. Thirty-six percent of the patients in this group had a favorable mRS score of $\leq 2$ at 90 days, which may be viewed as a vast improvement compared with reported mortality rates of $83-92 \%$ if the vessel fails to open with IA thrombolytic therapy [40,41]. The Multi MERCI trial was a subsequent iteration that included patients who were also treated with IV tPA [11]. Of note, there were no differences in the rates of intracranial hemorrhage or clinically significant procedural complications seen between those treated with IV tPA and those who were not, suggesting that pretreatment with IV TPA did not affect the safety of the procedure. Thirty-five percent of the patients with posterior circulation occlusion had a favorable outcome with an mRS score of $\leq 2$ in 90 days with the L5 Merci system [11].

The Penumbra thrombectomy device works by fragmenting and aspirating the thrombus (a representative case is shown in fig. 1). In a prospective, multicenter, single-arm study, 9 patients with basilar artery occlusion who presented within $8 \mathrm{~h}$ of symptom onset had a $38 \%$ observed mortality rate compared to the $88 \%$ expected mortality rate derived from the existing literature. These early data suggested that the penumbra device may have potential 

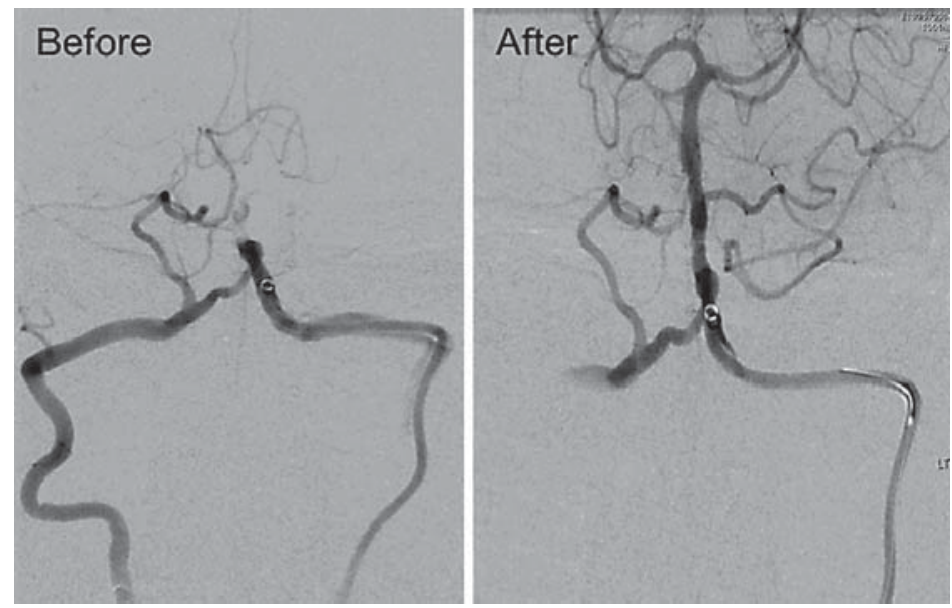

Fig. 2. A 54-year-old man with hypertension and dyslipidemia presented with nausea and vomiting, fluctuating left-sided weakness, and a fluctuating level of consciousness. A CT angiography demonstrated midbasilar occlusion, likely representing atherosclerotic disease. A Solitaire revascularization device was deployed across the basilar occlusion into the left posterior cerebral artery. Retrieval of the device resulted in complete revascularization of the basilar artery and its distal territories. A focal, severe, midbasilar stenosis was now demonstrable. This was successfully treated by angioplasty alone, using a Gateway PTA Balloon Catheter. A decision was made not to stent the vessel at this time, given the need for acetylsalicylic acid/Plavix in the context of an acute stroke syndrome.

as a treatment for basilar artery occlusion due to thromboembolism [42]. Data concerning the use of the Penumbra device in cases of basilar artery occlusions are often not reported separately from the entire study population [43-45].

The Trevo retriever is a stent retriever that applies a radial retrieval force within the thrombus and entraps the thrombus within the confines of the stent. A microcatheter is placed distal to the thrombus, and a retriever is deployed by unsheathing the microcatheter, resulting in the opening of the stent and radial displacement of the thrombus against the vessel wall, leading to the incorporation of the clot into the stent struts [46]. In an open-label, randomized, controlled trial that compared the efficacy of the Trevo device with that of the Merci device, it was found that 76 patients (86\%) in the Trevo group and 54 patients $(60 \%)$ in the Merci group met the primary endpoint of a thrombolysis in cerebral infarction score of $\geq 2$ [46]. The data suggest that the Trevo retriever may be more effective than the Merci retriever in clot retrieval. Compared with the Merci group, more patients in the Trevo group had good long-term functional outcomes at 90 days. In this trial, Trevo and Merci retrievers were used to treat $7(8 \%)$ and 5 patients (6\%) with vertebrobasilar strokes, respectively [46].

The Solitaire system is a self-extending, fully retrievable nitinol stent used for mechanical recanalization that is based on the Solitaire AB, which is commonly used for the stent-assisted treatment of intracranial aneurysms (a representative case is shown in fig. 2). In a prospective study by Mourand et al. [47], successful recanalization was achieved in 23 of 31 patients (74\%) within the first $24 \mathrm{~h}$ after the onset of symptoms. Five symptomatic intracranial hemorrhages were related to the procedure, and symptomatic distal migrations of thrombotic material occurred in 10 cases. A favorable outcome, measured at more than 180 days after the procedure, was observed in $35 \%$ of the patients with an overall mortality rate of $32 \%$ [47]. Costalat et al. [48] analyzed 16 cases of basilar occlusion that were treated with combined therapy, as part of the Rescue, Combined and Stand-Alone Thrombectomy (RECOST) study for large-vessel occlusions. Six patients had thrombectomy alone, and 10 had combination 
Yeung et al.: Endovascular Revascularization for Basilar Artery Occlusion

Table 1. Summary of previously published literature on different modalities of treatment for basilar artery occlusion

\begin{tabular}{|c|c|c|c|c|c|c|c|c|}
\hline Study & $\begin{array}{l}\text { Pa- } \\
\text { tients, } \\
\mathrm{n}\end{array}$ & $\begin{array}{l}\text { Hours } \\
\text { to treat- } \\
\text { ment }\end{array}$ & $\begin{array}{l}\text { Mortality, } \\
\%\end{array}$ & $\begin{array}{l}\text { Symptomatic } \\
\text { hemorrhage, } \\
\%\end{array}$ & $\begin{array}{l}\text { Recanalization, } \\
\%\end{array}$ & $\begin{array}{l}\text { Good } \\
\text { outcome } \\
\text { (mRS } 0-2), \%\end{array}$ & Study type & Notes \\
\hline \multicolumn{9}{|l|}{ Angioplasty } \\
\hline Imai et al. [10] & 10 & $<8.5$ & 40 & 10 & 80 & 20 & Retrospective & $\begin{array}{l}\text { Data taken from occlusion group; } \\
\text { mRS measured at } 3 \text { months }\end{array}$ \\
\hline BASICS [25] & 183 & & 54 & 1 & & & $\begin{array}{l}\text { Prospective, } \\
\text { observational }\end{array}$ & $\begin{array}{l}\text { Outcome assessed at } 1 \text { month; } \\
\text { more benefit for severe stenosis }\end{array}$ \\
\hline Jiang et al. [58] & 69 & & $13^{\mathrm{a}}$ & 1.5 & & & $\begin{array}{l}\text { Prospective, } \\
\text { database }\end{array}$ & - \\
\hline \multicolumn{9}{|l|}{ IA thrombolysis } \\
\hline Lindsberg and Mattle [9] & 344 & & 55 & 8 & 65 & 24 & Systematic review & - \\
\hline BASICS $[25]^{\mathrm{b}}$ & 92 & & 23 & 14 & 83 & 30 & $\begin{array}{l}\text { Prospective, } \\
\text { observational }\end{array}$ & Outcome assessed at 1 month \\
\hline BASICS $[25]^{\mathrm{c}}$ & 196 & & 49 & 14 & 69 & 11 & $\begin{array}{l}\text { Prospective, } \\
\text { observational }\end{array}$ & Outcome assessed at 1 month \\
\hline Renard et al. [26] & 16 & $<9.2$ & 50 & 0 & 69 & 31 & Prospective & - \\
\hline Kashiwagi et al. [27] & 18 & $<4.5$ & 6 & 6 & 94 & 39 & Retrospective & $\begin{array}{l}\text { With optional percutaneous } \\
\text { transluminal angioplasty }(n=8)\end{array}$ \\
\hline Yu et al. [28] & 52 & $<3-48$ & 38 & 12 & 77 & 42 & Retrospective & With optional stenting \\
\hline Chandra et al. [22] & 40 & $<7.2$ & 33 & 13 & 83 & 35 & Retrospective & $\begin{array}{l}\text { With optional angioplasty and } \\
\text { Merci thrombectomy }\end{array}$ \\
\hline Jung et al. [29] & 106 & $<5.5$ & 41 & 1 & 70 & 33 & $\begin{array}{l}\text { Prospective data } \\
\text { from registry }\end{array}$ & $\begin{array}{l}\text { With optional mechanical } \\
\text { thrombectomy; outcome } \\
\text { assessed at } 3 \text { months }\end{array}$ \\
\hline \multicolumn{9}{|l|}{ Mechanical thrombectomy } \\
\hline Lutsep et al. [59] & 27 & $<5.4$ & 44 & 19 & 78 & 33 & $\begin{array}{l}\text { Prospective, } \\
\text { nonrandomized, } \\
\text { multicenter trial }\end{array}$ & Adjunctive treatments used \\
\hline Pfefferkorn et al. [60] & 26 & $<6$ & 31 & 8 & 85 & 38 & Quasi-experimental & $\begin{array}{l}\text { Merci, Penumbra, or Angiojet } \\
\text { used in } 16 / 26 \text { patients }\end{array}$ \\
\hline Nogueira et al. [46] & 88 & $<8$ & $\begin{array}{l}29 \text { (Trevo) } \\
21 \text { (Merci) }\end{array}$ & $\begin{array}{l}7 \text { (Trevo) } \\
9 \text { (Merci) }\end{array}$ & $\begin{array}{l}86 \text { (Trevo) } \\
60 \text { (Merci) }\end{array}$ & $\mathrm{N} / \mathrm{A}$ & Clinical trial & Trevo vs. Merci \\
\hline Miteff et al. [61] & 10 & $<4$ & 30 & 10 & 100 & 20 & Retrospective & IA thrombolysis used \\
\hline Smith [38] & 111 & $<8$ & 33 & 9 & $\begin{array}{l}54 \text { without and } \\
69 \text { with adjunctive } \\
\text { therapy }\end{array}$ & 37 & Clinical trial & $\begin{array}{l}\text { Merci }-27 \% \text { received IV tPA } \\
\text { before the intervention; } \\
\text { outcomes assessed at } 3 \text { months }\end{array}$ \\
\hline Costalat et al. [48] & 16 & $<24$ & 25 & 2 & 81 & 44 & $\begin{array}{l}\text { Prospective data } \\
\text { from registry }\end{array}$ & $\begin{array}{l}\text { Solitaire }-10 / 16 \text { patients treated } \\
\text { with full-dose IV alteplase }\end{array}$ \\
\hline Bose et al. [42] & 9 & $<8$ & $38^{\mathrm{d}}$ & & 100 & & $\begin{array}{l}\text { Prospective, } \\
\text { single arm }\end{array}$ & - \\
\hline
\end{tabular}

therapy, which was immediate IVT as a bridging mechanism until the angiographic suite was ready for urgent thrombectomy. The mean recanalization time from symptom onset was 377 min. In these cases, $44 \%$ had a discharge NIHSS score of $0-1,44 \%$ had an NIHSS score improvement of $>9$ points, and the 3-month mortality was 33\% [48]. However, the outcome analysis was not made available for basilar artery thrombosis specifically.

\section{Results from the Basilar Artery International Cooperation Study}

Most of what we know about outcomes from endovascular interventions for basilar artery occlusion comes from retrospective case series (table 1). The Basilar Artery International Cooperation Study (BASICS) was the first organized, prospective, observational registry of consecutive patients who presented with an acute, symptomatic, and radiographically confirmed basilar artery occlusion that allowed comparisons of outcomes at 1 month between different treatment groups [25]. These treatment groups included (1) antithrombotic treatment only, (2) primary IVT including subsequent IA thrombolysis, and (3) IA therapy, 
which comprised thrombolysis, mechanical thrombectomy, stenting, or a combination of these approaches. Overall, $62 \%$ of the patients were treated within $6 \mathrm{~h}$ of symptom onset. Fifty-two percent of the patients had NIHSS scores of $>20$. They confirmed the poor prognosis after basilar artery occlusion, with a third mortality and a third dependency at 1 month. A key finding from this observational study was that there was no statistically significant superiority for any treatment strategy. However, there were trends to suggest that patients with a mild-to-moderate deficit more often had a poor outcome if they were treated with IA therapy rather than with IVT. Conversely, patients with a severe deficit seemed to benefit from both IVT and IA therapy. The absolute risk of death or dependency was 19\% (IVT) and 10\% (IA therapy) lower than the risk with antithrombotic treatment only [25]. From these data, one could argue that patients with minor symptoms may benefit from anticoagulation-/antithrombotic-based strategies alone rather than from aggressive IA interventions. However, an intrinsic flaw of the study lies in grouping patients treated with subsequent IA thrombolysis in the IVT group. It is difficult to assess the effectiveness of IA thrombolysis alone in basilar artery occlusion as IV tPA is the gold standard in the treatment of ischemic stroke, provided that a patient fits the inclusion criteria. It is, therefore, hard to conceive a study that subjects a patient to up-front IA therapy. Also, the current interpretation of the results from the BASICS is limited by the introduction of stent retrievers, which were not available at the time of the study.

Currently, at Yale-New Haven Hospital, the management of patients with acute basilar artery occlusion is based on the severity of symptoms. If the neurological deficits are mild, such as vertigo, nausea, and vomiting, then medical management with IVT is offered, if appropriate. This is corroborated by the BASICS [25]. IV tPA is given up to $4.5 \mathrm{~h}$ from symptom onset. If the deficits are more severe, such as hemiparesis, tetraparesis, and a fluctuating level of consciousness, then a more aggressive IA therapy is recommended after the administration of IV tPA. IA tPA is often given with mechanical revascularization as well. As there is little information about reperfusion and hemorrhage in basilar thrombosis, sometimes we perform an MRI to help assess the infarct burden before proceeding with IA delivery. Our center is able to perform acute MRI in a timely manner with the cooperation of the radiology department, which would prioritize stroke patients that may benefit from MRI with acute stroke sequences.

\section{Utility of Pretreatment MRI in Predicting Outcomes}

CT is known to be inferior in detecting brainstem ischemia [49-51]. Pretreatment MR diffusion-weighted imaging (DWI) has been shown to be a useful tool for predicting outcomes of basilar artery occlusions. Although some medical centers may not have the capability to perform MRI in a timely manner, there are sufficient data to demonstrate its utility in basilar artery occlusion.

Renard et al. [26] used a 10-point semiquantitative score composed of 1 point for unilateral and 2 points for bilateral involvement of each brainstem level (medulla, pons, and midbrain) and 0.5 points for each region and each side of the thalamus and temporooccipital lobe reflecting the number of acute ischemic brain lesions on DWI. In 16 patients treated with IA tPA, the authors found that a high lesion score was an additional predictor of poor outcome, defined as an $\mathrm{mRS}$ score of $>2$ [26].

Similarly, Cho et al. [52] analyzed baseline clinical and DWI parameters in 29 patients treated with endovascular procedures for acute basilar artery occlusion using a semiquantitative score based on arterial territory segmentation developed by Tatu et al. [53]. This scoring system is a summation of the territories involved: $0-8$ in the medulla, $0-6$ in the pons, and $0-8$ in the midbrain. The total number of involved arterial territories defined the 
brainstem DWI lesion score, ranging between 0 and 22 [53]. The outcomes at 3 months were dichotomized according to the mRS score into favorable (score of $0-2$ ) and unfavorable (score of 3-6) [52]. The patients were treated with various IA modalities including tPA, tPA with IV abciximab, tPA with mechanical thrombectomy, or mechanical thrombectomy alone. In multivariate analysis, the brainstem DWI score was the only independent baseline predictor of clinical outcome $(\mathrm{p}=0.026)$ [52].

Other pretreatment scores using DWI have also been published. Karameshev et al. [54] tested their score, which is a combination of those of Renard et al. [26] and Cho et al. [52], and showed that it reliably quantified pretreatment ischemic damage and was an independent predictor of functional outcome at 3 months. Similarly, a posterior circulation Acute Stroke Prognosis Early CT Score of $\geq 8$ points on early DWI is an independent predictor of a favorable outcome at 3 months in patients with acute basilar artery occlusion [55]. Although there are isolated reports of some functional recovery despite DWI evidence of infarction from basilar artery occlusion, the evidence supports DWI as a useful tool for prognostication. When available, it should be incorporated into future clinical trials and used in everyday practice when considering IA therapy for basilar artery occlusion [56, 57].

\section{Conclusions}

Basilar artery occlusion is a devastating disease due to the anatomic nature of the involved vessel. Various modalities of treatment are available, ranging from medical (antithrombotic, antiplatelet, and thrombolytic agents) to more aggressive endovascular interventions. There are many open questions due to the lack of prospective studies. The BASICS did not make a distinction between patients treated with IA thrombolysis or IVT [25]. The role of IA delivery during the early IVT time window will hopefully be elucidated in the upcoming BASICS. There is still a lack of data concerning the impact of bridging IV therapy on recanalization and reperfusion hemorrhage rates. There is also a paucity of prospective data on outcomes based on different interventions, specifically for the treatment of basilar artery occlusion. The newer generation of devices, such as stent retriever and Penumbra MAX systems, might be better than the older devices. The current data suggest that occlusions associated with severe clinical symptoms may benefit from endovascular interventions, while milder impairments may benefit from anticoagulation/antithrombotic treatments. Multicenter, prospective studies are warranted to compare the different treatment modalities.

\section{References}

1 Savitz SI, Caplan LR: Vertebrobasilar disease. N Engl J Med 2005;352:2618-2626.

2 Weimar C, Goertler M, Harms L, Diener HC: Distribution and outcome of symptomatic stenoses and occlusions in patients with acute cerebral ischemia. Arch Neurol 2006;63:1287-1291.

3 Mattle HP, Arnold M, Lindsberg PJ, Schonewille WJ, Schroth G: Basilar artery occlusion. Lancet Neurol 2011; 10:1002-1014.

4 Voetsch B, DeWitt LD, Pessin MS, Caplan LR: Basilar artery occlusive disease in the New England Medical Center Posterior Circulation Registry. Arch Neurol 2004;61:496-504.

5 Schulte-Altedorneburg G, Mayer TE: Management of acute basilar artery occlusion (in German). Radiologe 2007;47:355-358.

6 Baird TA, Muir KW, Bone I: Basilar artery occlusion. Neurocrit Care 2004;1:319-329.

-7 Schonewille WJ, Algra A, Serena J, Molina CA, Kappelle LJ: Outcome in patients with basilar artery occlusion treated conventionally. J Neurol Neurosurg Psychiatry 2005;76:1238-1241.

-8 The International Stroke Trial (IST): a randomised trial of aspirin, subcutaneous heparin, both, or neither among 19,435 patients with acute ischaemic stroke. International Stroke Trial Collaborative Group. Lancet 1997;349:1569-1581. 


\begin{tabular}{l|l}
\hline Intervent Neurol 2014;3:31-40 \\
\hline DOI: 10.1159/000368968 & $\begin{array}{l}\text { @ 2014 S. Karger AG, Basel } \\
\text { www.karger.com/ine }\end{array}$ \\
\hline
\end{tabular}

Yeung et al.: Endovascular Revascularization for Basilar Artery Occlusion

$\$ 9$ Lindsberg PJ, Mattle HP: Therapy of basilar artery occlusion: a systematic analysis comparing intra-arterial and intravenous thrombolysis. Stroke 2006;37:922-928.

10 Imai K, Mori T, Izumoto H, et al: Transluminal angioplasty and stenting for intracranial vertebrobasilar occlusive lesions in acute stroke patients. AJNR Am J Neuroradiol 2008;29:773-780.

11 Smith WS, Sung G, Saver J, et al: Mechanical thrombectomy for acute ischemic stroke: final results of the Multi MERCI trial. Stroke 2008;39:1205-1212.

12 Nagel S, Schellinger PD, Hartmann M, et al: Therapy of acute basilar artery occlusion: intraarterial thrombolysis alone vs bridging therapy. Stroke 2009;40:140-146.

13 Pfefferkorn T, Mayer TE, Opherk C, et al: Staged escalation therapy in acute basilar artery occlusion: intravenous thrombolysis and on-demand consecutive endovascular mechanical thrombectomy: preliminary experience in 16 patients. Stroke 2008;39:1496-1500.

14 Broderick JP, Palesch YY, Demchuk AM, et al: Endovascular therapy after intravenous t-PA versus t-PA alone for stroke. N Engl J Med 2013;368:893-903.

15 Ciccone A, Valvassori L, Nichelatti M, et al: Endovascular treatment for acute ischemic stroke. N Engl J Med 2013;368:904-913.

16 Kidwell CS, Jahan R, Gornbein J, et al: A trial of imaging selection and endovascular treatment for ischemic stroke. N Engl J Med 2013;368:914-923.

17 Lees KR, Bluhmki E, von Kummer R, et al: Time to treatment with intravenous alteplase and outcome in stroke: an updated pooled analysis of ECASS, ATLANTIS, NINDS, and EPITHET trials. Lancet 2010;375:1695-1703.

18 Vergouwen MD, Algra A, Pfefferkorn T, et al: Time is brain(stem) in basilar artery occlusion. Stroke 2012;43: 3003-3006.

19 Zeumer H, Hacke W, Ringelstein EB: Local intraarterial thrombolysis in vertebrobasilar thromboembolic disease. AJNR Am J Neuroradiol 1983;4:401-404.

-20 Macleod MR, Davis SM, Mitchell PJ, et al: Results of a multicentre, randomised controlled trial of intra-arterial urokinase in the treatment of acute posterior circulation ischaemic stroke. Cerebrovasc Dis 2005;20:12-17.

-21 Schulte-Altedorneburg G, Hamann GF, Mull M, et al: Outcome of acute vertebrobasilar occlusions treated with intra-arterial fibrinolysis in 180 patients. AJNR Am J Neuroradiol 2006;27:2042-2047.

22 Chandra RV, Law CP, Yan B, Dowling RJ, Mitchell PJ: Glasgow Coma Scale does not predict outcome post-intraarterial treatment for basilar artery thrombosis. AJNR Am J Neuroradiol 2011;32:576-580.

23 Smith WS: Intra-arterial thrombolytic therapy for acute basilar occlusion: pro. Stroke 2007;38(suppl):701703.

24 Eckert B, Koch C, Thomalla G, et al: Aggressive therapy with intravenous abciximab and intra-arterial rtPA and additional PTA/stenting improves clinical outcome in acute vertebrobasilar occlusion: combined local fibrinolysis and intravenous abciximab in acute vertebrobasilar stroke treatment (FAST): results of a multicenter study. Stroke 2005;36:1160-1165.

25 Schonewille WJ, Wijman CA, Michel P, et al: Treatment and outcomes of acute basilar artery occlusion in the Basilar Artery International Cooperation Study (BASICS): a prospective registry study. Lancet Neurol 2009;8: 724-730.

26 Renard D, Landragin N, Robinson A, et al: MRI-based score for acute basilar artery thrombosis. Cerebrovasc Dis 2008;25:511-516.

27 Kashiwagi J, Kiyosue H, Hori Y, et al: Endovascular recanalization of acute intracranial vertebrobasilar artery occlusion using local fibrinolysis and additional balloon angioplasty. Neuroradiology 2010;52:361-370.

28 Yu YY, Niu L, Gao L, et al: Intraarterial thrombolysis and stent placement for acute basilar artery occlusion. J Vasc Interv Radiol 2010;21:1359-1363.

29 Jung S, Mono ML, Fischer U, et al: Three-month and long-term outcomes and their predictors in acute basilar artery occlusion treated with intra-arterial thrombolysis. Stroke 2011;42:1946-1951.

-30 Sundt TM Jr, Smith HC, Campbell JK, Vlietstra RE, Cucchiara RF, Stanson AW: Transluminal angioplasty for basilar artery stenosis. Mayo Clin Proc 1980;55:673-680.

-31 Terada T, Higashida RT, Halbach VV, et al: Transluminal angioplasty for arteriosclerotic disease of the distal vertebral and basilar arteries. J Neurol Neurosurg Psychiatry 1996;60:377-381.

-32 Gupta R, Schumacher HC, Mangla S, et al: Urgent endovascular revascularization for symptomatic intracranial atherosclerotic stenosis. Neurology 2003;61:1729-1735.

33 Mori T, Kazita K, Chokyu K, Mima T, Mori K: Short-term arteriographic and clinical outcome after cerebral angioplasty and stenting for intracranial vertebrobasilar and carotid atherosclerotic occlusive disease. AJNR Am J Neuroradiol 2000;21:249-254.

-34 Hussain MS, Fraser JF, Abruzzo T, et al: Standard of practice: endovascular treatment of intracranial atherosclerosis. J Neurointerv Surg 2012;4:397-406.

-35 Ozturk AK, Bulsara KR: The evolving paradigm in the management of intracranial atherosclerotic disease. Int J Vasc Med 2012;2012:289852.

36 Berlis A, Lutsep H, Barnwell S, et al: Mechanical thrombolysis in acute ischemic stroke with endovascular photoacoustic recanalization. Stroke 2004;35:1112-1116.

-37 Smith WS, Sung G, Starkman S, et al: Safety and efficacy of mechanical embolectomy in acute ischemic stroke: results of the MERCI trial. Stroke 2005;36:1432-1438. 
38 Smith WS: Safety of mechanical thrombectomy and intravenous tissue plasminogen activator in acute ischemic stroke. Results of the Multi Mechanical Embolus Removal in Cerebral Ischemia (MERCI) trial, part I. AJNR Am J Neuroradiol 2006;27:1177-1182.

-39 Lu AY, Ansari SA, Nystrom KV, et al: Intra-arterial treatment of acute ischemic stroke: the continued evolution. Curr Treat Options Cardiovasc Med 2014;16:281.

40 Brandt T, von Kummer R, Müller-Küppers M, Hacke W: Thrombolytic therapy of acute basilar artery occlusion. Variables affecting recanalization and outcome. Stroke 1996;27:875-881.

-41 Bruckmann H, Ferbert A, del Zoppo GJ, Hacke W, Zeumer H: Acute vertebral-basilar thrombosis. Angiologicclinical comparison and therapeutic implications. Acta Radiol Suppl 1986;369:38-42.

42 Bose A, Henkes H, Alfke K, et al: The Penumbra System: a mechanical device for the treatment of acute stroke due to thromboembolism. AJNR Am J Neuroradiol 2008;29:1409-1413.

-43 Mpotsaris A, Bussmeyer M, Weber W: Mechanical thrombectomy with the Penumbra 3D Separator and lesional aspiration: technical feasibility and clinical outcome. Clin Neuroradiol 2014;24:245-250.

44 Kulcsar Z, Berentei Z, Marosfoi M, Vajda J, Szikora I: Thromboembolic complication induced stable occlusion of a ruptured basilar tip aneurysm. Case report and review of the literature. Interv Neuroradiol 2010;16: 83-88.

-45 Liu W, Kung DK, Mahaney KB, Rossen JD, Jabbour PM, Hasan DM: Anterior-to-posterior circulation approach for mechanical thrombectomy of an acutely occluded basilar artery using the Penumbra Aspiration System. World Neurosurg 2012;77:398.E17-E20.

-46 Nogueira RG, Lutsep HL, Gupta R, et al: Trevo versus Merci retrievers for thrombectomy revascularisation of large vessel occlusions in acute ischaemic stroke (TREVO 2): a randomised trial. Lancet 2012;380:1231-1240.

-47 Mourand I, Machi P, Milhaud D, et al: Mechanical thrombectomy with the Solitaire device in acute basilar artery occlusion. J Neurointerv Surg 2014;6:200-204.

48 Costalat V, Machi P, Lobotesis K, et al: Rescue, combined, and stand-alone thrombectomy in the management of large vessel occlusion stroke using the Solitaire device: a prospective 50-patient single-center study: timing, safety, and efficacy. Stroke 2011;42:1929-1935.

49 Roh JK, Kim KK, Han MH, et al: Magnetic resonance imaging in brainstem ischemic stroke. J Korean Med Sci 1991;6:355-361.

50 Fiebach JB, Schellinger PD, Jansen O, et al: CT and diffusion-weighted MR imaging in randomized order: diffusion-weighted imaging results in higher accuracy and lower interrater variability in the diagnosis of hyperacute ischemic stroke. Stroke 2002;33:2206-2210.

-51 Tei H, Uchiyama S, Usui T, Ohara K: Posterior circulation ASPECTS on diffusion-weighted MRI can be a powerful marker for predicting functional outcome. J Neurol 2010;257:767-773.

52 Cho TH, Nighoghossian N, Tahon F, et al: Brain stem diffusion-weighted imaging lesion score: a potential marker of outcome in acute basilar artery occlusion. AJNR Am J Neuroradiol 2009;30:194-198.

53 Tatu L, Moulin T, Bogousslavsky J, Duvernoy H: Arterial territories of human brain: brainstem and cerebellum. Neurology 1996;47:1125-1135.

54 Karameshev A, Arnold M, Schroth G, et al: Diffusion-weighted MRI helps predict outcome in basilar artery occlusion patients treated with intra-arterial thrombolysis. Cerebrovasc Dis 2011;32:393-400.

55 Nagel S, Herweh C, Köhrmann M, et al: MRI in patients with acute basilar artery occlusion - DWI lesion scoring is an independent predictor of outcome. Int J Stroke 2012;7:282-288.

56 Samaniego EA, Lansberg MG, DeGeorgia M, Venkatasubramanian C, Wijman CA: Favorable outcome from a locked-in state despite extensive pontine infarction by MRI. Neurocrit Care 2009;11:369-371.

57 Yoo AJ, Hakimelahi R, Rost NS, et al: Diffusion weighted imaging reversibility in the brainstem following successful recanalization of acute basilar artery occlusion. J Neurointerv Surg 2010;2:195-197.

58 Jiang WJ, Du B, Hon SF, et al: Do patients with basilar or vertebral artery stenosis have a higher stroke incidence poststenting? J Neurointerv Surg 2010;2:50-54.

59 Lutsep HL, Rymer MM, Nesbit GM: Vertebrobasilar revascularization rates and outcomes in the MERCI and Multi-MERCI trials. J Stroke Cerebrovasc Dis 2008;17:55-57.

60 Pfefferkorn T, Holtmannspötter M, Schmidt C, et al: Drip, ship, and retrieve: cooperative recanalization therapy in acute basilar artery occlusion. Stroke 2010;41:722-726.

-61 Miteff F, Faulder KC, Goh AC, Steinfort BS, Sue C, Harrington TJ: Mechanical thrombectomy with a selfexpanding retrievable intracranial stent (Solitaire $A B$ ): experience in 26 patients with acute cerebral artery occlusion. AJNR Am J Neuroradiol 2011;32:1078-1081. 